\title{
Utilization and associated factors of modern contraceptives during postpartum period among women who gave birth in the last 12 months in injibara town Awi Zone, North-West Ethiopia 2019
}

Getachew Andualem Belete ( $\sim$ getamid@gmail.com )

Bahir Dar University

Almaz Aklilu Getu

Bahir Dar University

Getahun Belay Gela

Bahir Dar University

Research article

Keywords: Postpartum, Modern contraceptives, Utilization, Northwest Ethiopia

Posted Date: October 31st, 2019

DOI: https://doi.org/10.21203/rs.2.16566/v1

License: (9) This work is licensed under a Creative Commons Attribution 4.0 International License. Read Full License 


\section{Abstract}

Background: The postpartum period is an important entry point for family planning service providers to reduce unintended and too closely spaced pregnancy. A postpartum modern contraceptive service is one of the recommended public health interventions for reducing maternal and child morbidity and mortalities. However, In Ethiopia modern contraceptive use during the postpartum period is low; resulting in unintended pregnancies and unwanted childbearing . there for this study was done to assess utilization and associated factors of modern contraceptives during the postpartum period among women who gave birth in the last 12 months in Injibara Town Awi Zone, North-Western Ethiopia.

Methods: A Community based cross-sectional study design was conducted from March 01 to 15/2019 on 400 women who gave birth in the last 12 months preceding the survey. A simple random sampling technique was used to recruit study subjects. Data was collected using interviewer-administered pretested and structured questionnaires. Data were entered using Epi data 3.5 and exported to SPSS version 23 for analysis. The association between variables was analyzed using Bivariate and multivariable logistic regression models and p-value $<0.05$ at $95 \%$ Confidence interval was considered as statistically significant.

Result: The prevalence of modern contraceptive utilization was 58.5\% (95\% Cl: 53.5-63\%) among postpartum mothers. Secondary school and higher educational levels [AOR=5.02; 95\% $\mathrm{Cl}(1.53-16.47)]$, $[A O R=4.25 ; 95 \% \mathrm{Cl}:(1.32-13.64)$ respectively)], previous history of abortion [AOR=3.93; 95\%, Cl: (1.4310.84)], having three and four antenatal care visit [AOR=4.74; 95\%, Cl: (1.94-11.54)] [AOR= 5.9; 95\%, Cl: (2.42-14.39) respectively], family planning counselling during antenatal care [AOR=2.81; $95 \%, \mathrm{Cl}$ : (1.634.86)], having postnatal care [AOR $=1.79,95 \%, \mathrm{Cl}$ : (1.09-2.96)], menses returning after birth [AOR=2.84, $95 \% \mathrm{Cl}$ : (1.77-4.57)] and resuming sexual activity [AOR=2.86, 95\% Cl: (1.71-4.78)] were factors affecting contraceptive use in postpartum period.

Conclusion : The prevalence of modern contraceptive use among postpartum women was found to be high in Injibara town. Therefore, strengthen family planning counseling during antenatal care and postnatal care to reduce the missed opportunity of postpartum women to get family planning methods, especially long-acting reversible contraceptives.

\section{Background}

Family planning is defined as the ability for individuals and couples to attain their desired number of children in a family when to have children and an age interval between children through the use of contraceptive methods [1].

Worldwide, more than $90 \%$ of women during the postpartum period want to either delay or avoid future pregnancies. However, in most cases, sexual activity is resumed without using any contraceptive method [2]. 
The advantage of family planning has become increasingly recognized internationally to improve health and social outcomes of women and families, as well as public health, economic, and environmental benefits at a different level [3].

The postpartum period is the first 12 months following childbirth which is critical for addressing widespread unmet needs in family planning and for reducing the risks of closely spaced pregnancies [4].

The recommended time for the initiation of contraceptives in the postpartum period is 6 weeks after delivery but most women do not start taking contraceptives at the recommended time [2].

The first years after delivery is an important entry point for family planning service provision; however, women in Ethiopia are usually not the use of family planning methods during this period evidence has been shown that nearly half (47\%) of pregnancies occur within a short birth interval of fewer than two years after the preceding birth [5].

When a mother becomes pregnant early after childbirth, she is more likely to develop complications including, spontaneous abortion, postpartum bleeding, and anemia, low birth weight newborn and/or preterm. The earlier delivered child may not receive adequate care and support which, thereafter, could lead to vulnerabilities to disease and malnutrition[3].

Women are more likely to engage with the healthcare system during antenatal care, delivery, postnatal care, and first-year infant immunizations. Each of these encounters is an opportunity for health care workers to integrate family planning into their existing counseling and services to better meet the needs of postpartum women[4].

Pregnancies that are either too early, too close, too many or too late, expose mothers to high morbidity and mortality during pregnancy and childbirth. Family planning can reduce maternal mortality by reducing the number of pregnancies, the number of abortions, and the proportion of births at high risk $[6,7]$.

In Ethiopia, maternal mortality is an important public health issue; 412 per 100, 000 live births are dying as a result of complications related to pregnancy and childbirth, among the highest in the Sub-Saharan Africa countries [8].

Determining the level and associated factors of postpartum contraceptive utilization have the potential to contribute to achieving the Ethiopian Health Sector Transformation Plan (EHSTP) and to the Sustainable Development Goals (SDGs) [9].

Currently, in Ethiopia, family planning services are integrated into maternal and child health care services at all levels of the health care delivery system and the service has been provided to the rural communities at the health posts through health extension workers. Maximal efforts have been performed by the government, local and international partners on FP programs [10].

Despite all these efforts, the national modern contraceptive prevalence rate and unmet need for family planning were reported as $35 \%$ and $22 \%$ respectively in the Ethiopian demographic health survey report 
2016, which was lower than the global family planning targets[8]. Besides, the prevalence of FP utilization was varied in different parts of the community; Hadiya zone (23.9\%), South Gondar zone (66.2\%), Gedeo zone (64.2\%), Illubabor zone (44.9\%) [11].

\section{Methods}

\section{Study design}

A Community based cross-sectional study was conducted in Injibara Town, Amhara Region, among women who gave birth in the last 12 months preceding the survey.

Study area and period

The study was conducted in Injibara Town, Awi Zone Amhara Regional State, Ethiopia from March 01 to 15/2019 among women who gave birth in the past 12 months.

Injibara Town is found in the southwestern part of the region and northwestern part of Ethiopia. It is located about $447 \mathrm{~km}$ away from Addis Ababa the capital city of Ethiopia and $118 \mathrm{~km}$ from Bahirdar city of Amhara National regional state. Agew Awi zone is one of the 13 zones in the Amhara region of Ethiopia. It is bordered on the West by Benishangul Gumuz Region, on the North by North Gondar zone, and on the East by West Gojjam. The administrative zone of Awi is Injibara; other towns include Chagni and Dangila.

According to the information obtained from the Injibara town health office, the town has five Kebeles and the current total population was 46,745 of whom, 23,466 are female and women of reproductive age were about 11,048 and 1,578 mothers who were delivered in the last year. There is one general hospital, one public health centers, five health post, five private clinics and nine drug shops providing maternal and other health services to the population [12].

\section{Source population}

All mothers who gave birth for the last 12 months in Injibara Town

\section{Study population}

All mothers who gave birth for the last 12 months in Injibara Town

\section{Sample size determination}

Sample size is calculate by using a single population proportion formula based on $45.8 \%$ proportion of postpartum modern contraceptive use in Gondar town [13] at 5\% margin of error (d) and 95\% (za/2 = 1.96) 


$$
\begin{gathered}
\mathrm{n}=(\underline{\mathrm{Z} \alpha / 2})^{\underline{2}} \underline{\mathrm{P}}(\underline{1-\mathrm{P}})- \\
\mathrm{d}^{2} \\
\mathrm{n}=(\underline{(1.96)})^{\underline{2}} \underline{\mathrm{x} 0.458 \times 0.542}=381.449=382 \\
(0.05)^{2}
\end{gathered}
$$

Where;

$p=$ prevalence of postpartum modern family planning (45.8\%)

$d=$ marginal error between the samples and population $(0.05)^{2}$

$\mathrm{Z} \alpha / 2=$ critical value at $95 \%$ certainty $(1.96)^{2}$

$\mathrm{n}=$ calculated sample size $=382$

And adding $5 \%$ contingency for non-respondents, the final sample size become $=402$

\section{Sampling procedure}

All fives Kebeles of the town were included in the study. The total sample size $(n=402)$ was allocated by using proportional allocation by size, as applied to the total number of postpartum women in the Kebeles. Before data collection, a census was conducted to identify postpartum women in each Kebele. The total number of postpartum women in the last 12 months was 1,578. The study participants were selected by simple random sampling techniques. In case when the study participants are not able to interview for some reason, an attempt is made three times to interview the respondent and after all, they were considered non-respond. The lottery method was used if more than one mother who gave birth for the last 12 months found in the same house.

\section{Inclusion and Exclusion criteria}

\section{Inclusion criteria}

Women who gave birth in the last 12 months and lived in the area at least for six months preceding the survey regardless of their birth outcome were included in the study 


\section{Exclusion criteria}

- Women who are hysterectomy was performed

\subsection{Variables}

- Dependent variable:-Postpartum modern contraceptive utilization

- Independent variables

- Socio-economic and demographic factors

(Age, marital status, educational status, religion, ethnicity and occupation)

- Health service related factors

(ANC, Place of delivery, PNC, FP counseling during pregnancy, FP counseling after delivery, and Getting linked for family planning during child immunization, Number of live children and infant sex)

- Knowledge and attitude of postpartum family planning

- Reproductive health related (fertility desire, Number of live children, infant sex, sexual resumption, menstrual resumption).

\section{Operational definition}

Postpartum period - the time from birth up to one year [2]

Postpartum modern contraceptive utilization - a postpartum woman's current use of any modern contraception methods (pills, IUCD, injectable, condom (male or female), sterilization (male or female), implants) during the 12 months following her recent childbirth [14].

Good knowledge- is defined as a knowledge score of greater than or equal to the mean knowledge score $[13,15]$

Poor knowledge- is defined as a knowledge score of less than the mean knowledge score $[13,15]$

Favorable attitude -is defined as an attitude score of greater than or equal to the mean attitude score [13, $15]$

Unfavorable attitude- is defined as an attitude score of less than the mean attitude score $[13,15]$

\section{Data collection instruments}


The data were collected from mothers who gave birth for the last 12 months by using a pre-tested and structured questionnaire adapted from different kinds of literature which are developed for similar purpose done by different authors. The data collection tool (questionnaire) was prepared first in English and then translated to a local language (Amharic and Awigni) and then re-translated back to the English language by a language expert. The questionnaire comprises socioeconomic and demographic characteristics, reproductive history and maternal health care, Knowledge and current practice of postpartum modern contraceptive use, the experience of contraception services and sexuality issue related variables.

\section{Data collection procedure}

Data were collected by 5 diploma midwives and Two BSc midwives for supervision. Interviewer administers questionnaires via face to face interview was used to collect the data. A sampling frame was obtained from census and study subjects were selected by using simple random sampling techniques.

\section{Data quality control}

To assure the quality of the data, technical training for two days was given for data collectors and supervisors about the objective of the study, methods, and significance of the study. Before undertaking actual data collection, questionnaires were pre-tested in randomly selected 20 postpartum women (5\% of the sample) nearer to Injibara town at Addis Kidam that has similar characteristics with the study population to ensure the clarity of the questionnaire, to check the wording, and to confirm the logical sequence of the questions and necessary corrections was employed on the tool based on the pre-test accordingly. Every night each questionnaire was reviewed \& checked by supervisors \& PI and feedback was given to data collectors the next morning. Supervisors were strictly following the data collection process and check for missed information by two BSc midwives and principal investigator

\section{Data analysis}

Data were cleaned, coded and entered by using Epi-Data version 3.1 and then exported to SPSS (statistical package for social science) version 23 for analysis. All require variables recoding and transformation were done before the final data analysis. Firstly, descriptive statistics (frequency, tables, and figures) used to summarize the data. Secondly, bivariate analyses were done for the independent variables with the outcome variable to select candidate variables for the multivariate analyses. Variables having $p$-value < 0.2 in the bivariate analyses were fitted into a multivariable logistic regression to control the effects of confounding. Finally, variables that have a P-value of less than 0.05 were considered to declare significance. Adjusted odds ratios with their $95 \% \mathrm{Cl}$ calculated to determine the strength and presence of an association.

To assess the knowledge and attitude of participants towards postpartum family planning multiple questions were asked with 13 questions. Seven for assessing knowledge of contraceptive and six questions to assess the attitude of contraceptives. The mean score was calculated for knowledge and 
attitude variables separately. Any score greater or equal to the mean score was defined as a high score and hence labeled as "good knowledge" for knowledge variable while it was labeled as "favorable attitude" for attitude variable. Any score which is less than the mean score was defined as low score and hence labeled as "poor knowledge" and "unfavorable attitude" for knowledge and attitude variables respectively $[13,15]$.

\section{Results}

\section{Socio- demographic characteristics of participants}

A total of 400 postpartum mothers participated with a response rate of $99.5 \%$. The mean age of the respondents was $26.82( \pm 4.87 \mathrm{SD})$. The minimum and the maximum age of the respondents were 18 and 40 years respectively. Nearly half (41.5\%) of the respondents were between the age of 25 and 29 years.

Majority of the women 324(81\%), were a follower of Orthodox Christian and about $321(80.2 \%)$ of the study participants were from Agew. More than three-fourth of the participants, 376(94\%), were married and 161(40.2\%) were housewives. Of the study participants, 144(36 \%) had attained a Higher level of education. (Table 1)

\section{Reproductive and maternal health service use-related characteristics of the study participants}

The median numbers of pregnancies of the respondents were 2 (IQR \pm 2$)$. One hundred forty-one (36.8\%) of the participants had a birth interval of 2-3 years. During their last pregnancy, 159(39.7\%) of the respondents received four and above ANC follow up, 127(31.8\%) were counseled on family planning methods during ANC.

Regarding the place of delivery for the last birth of the respondents, 341 (85.2\%) gave birth in a government health institution, 54(13.5\%) in private health institutions and 5(1.3\%) at home.

Sixty-eight $(17 \%)$ of the study participants had already started sexual intercourse after giving birth and more than half $(54.8 \%)$ of respondents resumed menses, and the rest were still amenorrheic. (Table 2 )

\section{Knowledge and attitude of Mothers towards modern contraceptive methods}

All study participants were heard about modern contraceptive methods and more than half $(62 \%)$ of them were knowledgeable about postpartum modern contraceptive.

Concerning the attitudes of the respondents towards postpartum contraceptive utilization more than half (53.5\%) of them had unfavorable attitudes. (Table 3 ) 


\section{Utilization of modern contraceptive method during the postpartum period}

The prevalence of modern contraceptive use among women in the postpartum period was found to be $58.5 \%(95 \% \mathrm{Cl}: 53.5,63)$. The most commonly used contraceptive method was injectables $91(39 \%)$ followed by implant 78(33\%) and oral pills $43(19 \%)$ respectively. (figer1).

Among currently contraceptives users 103 (44\%) of women start to use contraceptives methods from 6 weeks to 3 months. More than half $(63.7 \%)$ of postpartum mothers start contraceptive used after menses resumes. (Table 4).

Reasons for not using contraceptive methods

Less than half, $(41.5 \%)$ of the women in the postpartum period did not currently use any modern contraceptive at the time of the interview. The major reasons for not currently using contraceptives were feeling of not exposed to the risk of pregnancy due to amenorrhea after birth $48(29 \%)$, followed by were feeling of not exposed to the risk of pregnancy due to breastfeeding $36(22 \%)$ and partner opposed to use family planning $28(17 \%)$ (Figure2).

\section{Bivariate and multivariate analysis of factors associated with the utilization of modern contraceptives during postpartum period}

In bi-variate analysis: Maternal education level, knowledge about modern family planning methods, number of ANC visit, family Planning counseling during antenatal care, previous use of family planning, previous history of abortion, having postnatal care, menses returned after birth, sexual resumption after delivery and favourable attitude about family planning were found to be associated with utilization of family planning.

In the multivariate logistic regression analysis, the following seven variables were identified as independently associated with postpartum modern contraceptive use. These were: Maternal educational status, number of ANC visit, family Planning counseling during antenatal care, previous history of abortion, having postnatal care, menses returned and sexual resumption.

Women who attended secondary school 5 times more likely to use postpartum modern contraceptive than those who was unable to read and write $[A O R=5.02 ; 95 \% \mathrm{Cl}(1.53-16.47)]$ and those with higher education were 4.2 times more likely to use postpartum modern contraceptive than those who was unable to read and write $[\mathrm{AOR}=4.25 ; 95 \% \mathrm{Cl}:(1.32-13.64)]$.

Women who had a history of abortion almost four times more likely to use postpartum modern contraceptives as compared to those women who had no history of abortion [AOR $=3.93$; 95\%, Cl: (1.43- 
10.84)].

Women who had three ANC visit during pregnancy were 4.7 times more likely to use postpartum modern contraceptives compared to those women who had one ANC visit during pregnancy [AOR $=4.74 ; 95 \%, \mathrm{Cl}$ : (1.94-11.54)] and those who had four ANC visit almost six times more likely to use postpartum modern contraceptives compared to those women who had one ANC visit during pregnancy $[A O R=5.9 ; 95 \%, \mathrm{Cl}$ : (2.42-14.39)].

Women who have received family planning counseling during antenatal care were 2.8 times more likely to use modern contraceptives in the postpartum period than those who did not [AOR $=2.81 ; 95 \%$, Cl: $(1.63-$ 4.86)].

Women who attended postnatal care were nearly two times higher odds to use modern contraceptives in the postpartum period than compared to women did not attend postnatal care [AOR $=1.79,95 \%, \mathrm{Cl}$ : (1.092.96)].

Postpartum women who started menstruation were about 2.8 times [AOR $=2.84,95 \% \mathrm{Cl}$ : (1.77- 4.57)] more likely to use contraceptives in the postpartum period as compared to those who were amenorrheic.

The likelihood of using contraceptives in the postpartum period was 2.8 times higher among postpartum women who started sexual activity compared with abstainers [AOR $=2.86,95 \% \mathrm{Cl}$ : $(1.71-4.78)]$. (Table 5)

\section{Discussion}

This study showed that the prevalence of modern contraceptive use among postpartum women was 58.5\% [95\%, Cl: (53.5 - 63)]. Injectable (38.9\%) and Implants (33.3\%) were the most frequently used methods.

This finding is in line with a study conducted in Kenya (59\%) [16]. This similarity might be due to similar socio-demographic characteristics. For instance, the proportion of women who were married in this study was $94 \%$, and in the Kenya study, it was $88 \%$. The educational level of the two study participants was almost similar.

Postpartum contraceptive use in this study was higher than other studies conducted in Ethiopia like Gondar (45.8\%) [13],Dabat (10.3) [17], Debre Berhan (41.6\%) [18], Aksum (48\%)[14], Gida Ayana district Oromia region (45.4\%) [19] and EDHS 2016(23\%)[20]. The difference could be due to the time gap of studies, study participant, socio-demographic and reproductive characteristics variation. The study conducted in Gondar, study participants were postpartum women in the extended postpartum period (6 weeks -12 months). But in this study, all postpartum (immediate postpartum up to 12 months) were included. The proportion of women who had higher education was lower $(20.6 \%)$ than this study $(36 \%)$. The study design was institutional-based but in this study community-based. 
The study conducted in Debre Berhan study participants were in the extended postpartum period (6 week -12 months). But in this study all postpartum women who gave birth in the last 12 months

The study conducted in Gida Ayana women who had 4 or more ANC visits were (28.5\%) lower than this study $(39.7 \%)$ and $50.2 \%$ women delivered at home which is high compared to this study only $(1.3 \%)$ of women delivered at home. More than half $(54.7 \%)$ of the respondents were not able to read and write but in this study low (5\%). And also a difference in study setting since conducted in rural areas but this study conducted primarily in urban settings were access and service utilization would be high compared from rural.

The study conducted at Dabat district in which the proportion of women who could not read and write was (64.4\%). it's higher than from this study (5.2\%).

Another possible reason for the difference in PPFP use among postpartum women might be differences in prenatal service utilization. Mothers who had postnatal care visits were higher in this study $(77.5 \%)$ than the study done in Aksum northern Ethiopia (43.7\%).

It was also higher than studies conducted in Uganda (28\%)[[21]. The difference could be due to reproductive characteristics variation. The marital status of women may have contributions to the differences in the prevalence of postpartum family planning utilization. If a woman is married, she may have early postpartum sexual contact than those who are not married. The proportion of our participants who were married was higher (94\%) than that of the study done in Uganda (83.6). However, this finding was found to be lower compared with the study done in Addis Ababa (80.3\%) [22] and Ganta-Afeshum District Eastern Tigray (68.1\%) [23]. The difference could be due to the presence of socio-economic and reproductive variation and service accessibility.

Study was done in Addis Ababa (89.5\%) pregnancy was planned but this study (14.3\%) recent pregnancy was unplanned, more than three fourths $(78.3 \%)$ had histories of family planning use before their last pregnancies but in this study only $(7.3 \%)$ participant had histories of family planning use and also living condition, access, and service utilization would be high compared from this study.

Study conducted in Ganta-Afeshum District Eastern Tigray (68.1\%) women who had 4 or more ANC visits were $(90.5 \%)$ higher than this study $(39.7 \%)$ and study participant was resumed sexual activity $(68.3 \%)$ higher than this study (17\%).

It was also lower than studies conducted in Rural Kenya (86.3\%)[24] andNtchisi district hospital Malawi (75\%)[25]. Study conducted in Malawi (90.2\%) of the participants had resumed sexual activity which was higher than this study (17\%). Over half of the respondents (58.5\%) were used FP methods before pregnancy higher than from this study (7.3) and also both in Kenya and Malawi it might be due to policy; access and service utilization of postpartum family planning was high.

The odds of modern contraceptive utilization significantly increased as the educational level of women increases. Women who were at higher educational level 4.2 times increase the odds of using modern 
contraceptive methods than not educated and also women who were at secondary school 5 times increase the odds of using modern contraceptive methods than not educated.

This finding is supported by previous studies conducted in Northern Ethiopia and the Kebribeyah town Somali Region[14, 15] and Rural Kenya [24]. The possible explanation could be women's educational attainment increases, health service seeking behavior increases and a better understanding of benefits of birth spacing, limited family size and available methods of family planning. Besides the level of awareness about family planning and health-seeking behavior increased from those who have not been educated.

The odds of three ANC visits during pregnancy were 4.7 times higher to utilize postpartum contraceptives than women who had one ANC visit during pregnancy and similarly the odds of four ANC visits during pregnancy were almost six times higher to utilize postpartum contraceptive than women who had one ANC visit during pregnancy. This study was supported by a cross-sectional study conducted in GantaAfeshum District Eastern Tigray [23] Kebribeyah Town Somali Region[15], and Aroressa District, Southern Ethiopia [26] and India [27]. It could be that women who had frequent ANC visits had more exposure to information and had more awareness of birth spacing and complications of early delivery for both mother and newborn.

In this study women who had Family planning counseled during antenatal care were 2.8 times more likely to utilize postpartum family planning than their counterparts. This study is supported by across sectional survey conducted in Northern Ethiopia, Kebribeyah Town Somali Region and Aroressa District $[14,15,26]$.

This might be due to women who were proper counseled about available methods of family planning and the consequences of frequent birth during ANC by providers. However, a study done in Kenya shows that discussing FP in ANC alone was not associated with effective contraceptive use[16].

Women who had attended postnatal care were 1.7 times higher odds of using modern contraceptives in the postpartum period than to their counterparts. This is similar to a study done in Aroressa District Southern Ethiopia [26],Northern Ethiopia[14] and rural Tigray [28].

This might be due to that postnatal care visits give good opportunity counseling about the advantage and disadvantages of family planning use, birth space, and maternal and child health service. It leads to using of modern contraceptive methods in an effective and timely manner.

Women whose menses was returned after last delivery were 2.8 times more likely to use postpartum contraceptive than those who haven't seen menses. This finding is also supported by other studies done in Ethiopia Debre Birhan town, Gondar town, Aroressa District Southern Ethiopia [13, 18, 26] and Malawi [25].

This finding could be justified by postpartum women whose menses are returned after delivery may assume that they are at risk of getting pregnant, so this can initiate them to start postpartum contraceptive utilization on time. But amenohorric women would perceive less vulnerable to get pregnancy by assuming that amenorrhea would protect against pregnancy irrespective of the postpartum duration. 
Most mothers dose not start using contraceptive until menses has returned regardless of the time of the postpartum period, which can be risky.

The odds of resuming sexual activities were 2.8 times higher to use postpartum modern contraceptive than the counterpart. A similar finding was seen in studies done in Debre Birhan[18], Northern Ethiopia[14], Gondar town[13]. This could be due to women resume sexual activities; they perceive exposed to the risk of unintended pregnancy then they motivate to use contraceptive methods. Therefore, resuming sexual activities is strongly linked to the initiation of modern contraceptives in the postpartum period.

Women who were the previous history of abortion almost four times more likely use postpartum modern contraceptives as compared to their counterparts. This might be due to family planning is one component of post-abortion care. Risk of pregnancy after abortion counseled by health providers

\section{Conclusion}

The prevalence of modern contraceptive use among postpartum women was found to be high in Injibara town as compared to EDHS 2016. Maternal educational status, parity, knowledge about modern contraceptive methods, number of ANC visit, family Planning counseling during antenatal care, having postnatal care, menses returned and sexual resumption was significantly associated with modern contraceptive use among postpartum women

\section{List Of Abbreviations}

ANC Antenatal Care

EDHS Ethiopia Demographic Health Survey

EHSTP Ethiopia Health Sector Transformation Plan

FP Family Planning

HSDP Health Sector Development Program

IUCD Intra Uterine Contraceptive Device

LARC Long Acting Reversible Contraceptive

OCP Oral Contraceptive Pills

PNC Postnatal Care

PPFP Postpartum Family Planning

SDG Sustainable Development Goals 
STI Sexual Transmitted Infection

WHO World Health Organization

\section{Declarations}

\section{Ethics approval and consent to participate}

Ethical approval was obtained from the Institutional review board of Bahir Dar University College of medicine and health sciences. The letter of permission was also obtained from the midwifery department and Injibara town health office administration for respective kebeles before the study has taken place both to ensure legitimacy and build trust with kebeles and study communities. After the purpose and objective of the study are informing, both verbal \& written consent was obtained from each study participant.

All information gained during data collection kept confidential and any personal identification not recorded on the questionnaire. Participants were informed about they have the right to withdraw from the study at any time if they are not comfortable with the questionnaire.

\section{Consent for publication}

Not applicable

\section{Availability of data and material}

The data supporting this finding can be available at any time with request from the BMC pregnancy and child birth.

\section{Competing interests}

The authors declare that they have no competing interests.

\section{Funding}

Bahir Dar University.The funder has no any role for designing of the study, data collection, analysis and interpretation of the data and writing up of the manuscript.

\section{Authors' contributions}

GA wrote the proposal, participated in data collection, analyzed the data and drafted the paper. GA, AA, and GB approved the proposal with some revisions, participated in data collection, analysis and manuscript writing. All authors read and approved the final manuscript.

\section{Acknowledgements}

First of all, we would like to forward our deepest gratitude to Bahir Dar University, college of medicine and health science for financial support to conduct this research and APHI was given the official permission 
letter. Our special thanks and appreciation goes to all the study participants who voluntarily participated in this study and health care personnel of the Awi zone administrative office and for their consistent support.

\section{References}

1.Organization, W. H. and W. H. O. M.o.S. A. Unit, Global status report on alcohol and health, 20142014: World Health Organization.

2.Organization, W. H., WHO/ Family planning/contraception: fact sheet No 351. 2015. Available from:.[Last accessed on 2016 Dec 26]. Back to cited text, (1).

3.Bakamjian, L., Programming strategies for postpartum family planning. 2013.

4.Gaffield, M. E., S. Egan, and M. Temmerman, It's about time: WHO and partners release programming strategies for postpartum family planning. Global Health: Science and Practice, 2014. 2(1): p. 4-9.

5.Initiative, A. F. P., US Agency for International Development, Family planning needs during the extended postpartum period in Uttar Pradesh, India, 2008, 2010.

6.CSACE, I., Ethiopia Demographic and Health Survey 2016. Addis Ababa, Ethiopia, and Rockville, Maryland, USA: CSA and ICF, 2016.

7.Howie, P., et al., Fertility after childbirth: post-partum ovulation and menstruation in bottle and breast feeding mothers. Clinical endocrinology, 1982. 17(4): p. 323-332.

8.Singh, M., et al., Awareness and acceptance of contraception in post-partum women in a tertiary care hospital of Delhi. International Journal of Reproduction, Contraception, Obstetrics and Gynecology, 2017. 4(3): p. 690-695.

9.Assefa, T., et al., Physician distribution and attrition in the public health sector of Ethiopia. Risk management and healthcare policy, 2016. 9: p. 285.

10.Tigabu, S., et al., Access to and utilization of quality family planning services: challenges and opportunities in meeting FP2020 targets. IJHSR, 2016. 6(1): p. 424e33.

11. Hamdalla, T., A. Arega, and T. Markos, Prevalence and associated factors of modern contraceptive utilization among married women in reproductive age group in Misha Woreda Hadiya Zone, South Ethiopia. J Women's Heal Care, 2017. 6: p. 3.

12.Edhs, M., Ethiopia Mini Demographic and Health Survey. Ethiopia: Central Statistical Agency Addis Ababa, 2014.

13.Berta, M., et al., Utilization and associated factors of modern contraceptives during extended postpartum period among women who gave birth in the last 12 months in Gondar Town, northwest Ethiopia. Ethiopian Journal of Health Sciences, 2018. 28(2): p. 207-216. 
14.Abraha, T. H., A. S. Teferra, and A. A. Gelagay, Postpartum modern contraceptive use and associated factors in Northern Ethiopia. Epidemiology and Health, 2017.

15.Nigussie, A., D. Girma, and G. Tura, Postpartum family planning utilization and associated factors among women who gave birth in the past 12 months, Kebribeyah Town, Somali Region, Eastern Ethiopia. J Women's Health Care, 2016. 5: p. 340.

16.Achwoka, D., et al., Uptake and correlates of contraception among postpartum women in Kenya: results from a national cross-sectional survey. Contraception, 2018. 97(3): p. 227-235.

17.Mengesha, Z. B., A. G. Worku, and S. A. Feleke, Contraceptive adoption in the extended postpartum period is low in Northwest Ethiopia. BMC pregnancy and childbirth, 2015. 15(1): p. 160.

18.Demie, T., et al., Postpartum Family Planning Utilization among Postpartum Women in Public Health Institutions of Debre Berhan Town, Ethiopia. J Women's Health Care, 2018. 7(426): p. 21670420.1000426.

19.Teka, T. T., et al., Role of antenatal and postnatal care in contraceptive use during postpartum period in western Ethiopia: a cross sectional study. BMC research notes, 2018. 11(1): p. 581.

20.Tessema, G. A., et al., Association between skilled maternal healthcare and postpartum contraceptive use in Ethiopia. BMC pregnancy and childbirth, 2018. 18(1): p. 172.

21.Rutaremwa, G., et al., Predictors of modern contraceptive use during the postpartum period among women in Uganda: a population-based cross sectional study. BMC Public Health, 2015. 15(1): p. 262.

22. Gebremedhin, A. Y., et al., Family planning use and its associated factors among women in the extended postpartum period in Addis Ababa, Ethiopia. Contraception and reproductive medicine, 2018. $3(1):$ p. 1.

23.Gebremariam, A. and H. Gebremariam, Contraceptive use among lactating women in Ganta-Afeshum District, Eastern Tigray. International Breastfeeding Journal, 2016. 11(4).

24.Jalang'o, R., et al., Determinants of contraceptive use among postpartum women in a county hospital in rural KENYA. BMC Public Health, 2017. 17(1): p. 604.

25.Bwazi, C., et al., Utilization of postpartum family planning services between six and twelve months of delivery at Ntchisi District Hospital, Malawi. Health, 2014. 6(14): p. 1724.

26.Dona, A., et al., Timely initiation of postpartum contraceptive utilization and associated factors among women of child bearing age in Aroressa District, Southern Ethiopia: a community based cross-sectional study. BMC Public Health, 2018. 18(1): p. 1100.

27.Revanna, R. and N. Agadi, Determinants of Post-partum contraception practices in urban slums of central Karnataka, India. Indian Journal of Community Health, 2016. 28(3): p. 280-285. 
28.Abraha, T. H., et al., Predictors of postpartum contraceptive use in rural Tigray region, northern Ethiopia: a multilevel analysis. BMC Public Health, 2018. 18(1): p. 1017.

\section{Tables}

Table 1 Distribution of the study population by socio-demographic characteristics, Injibara town, Northwest Ethiopia, April 2019 ( $\mathrm{n}=400)$ 


\begin{tabular}{|c|c|c|}
\hline \multicolumn{3}{|l|}{ Maternal age } \\
\hline$\leq 19$ years & 22 & 5.5 \\
\hline 20-24 years & 122 & 30.5 \\
\hline 25-29 years & 166 & 41.5 \\
\hline 30-34 years & 59 & 14.8 \\
\hline$\geq 35$ years & 31 & 7.7 \\
\hline \multicolumn{3}{|l|}{ Marital status } \\
\hline Single & 10 & 2.5 \\
\hline Married & 376 & 94 \\
\hline Others* & 14 & 3.5 \\
\hline \multicolumn{3}{|l|}{ Religion } \\
\hline Orthodox & 324 & 81 \\
\hline Muslim & 49 & 12.2 \\
\hline Others** & 27 & 6.8 \\
\hline \multicolumn{3}{|l|}{ Ethnicity } \\
\hline Agew & 321 & 80.2 \\
\hline Amhara & 60 & 15 \\
\hline Others*** & 19 & 4.8 \\
\hline \multicolumn{3}{|l|}{ Educational status } \\
\hline Unable to read and write & 21 & 5.2 \\
\hline Read and write & 27 & 6.8 \\
\hline primary $(1-8)$ & 99 & 24.8 \\
\hline secondary $(9-12)$ & 109 & 27.2 \\
\hline Higher education & 144 & 36 \\
\hline \multicolumn{3}{|l|}{ Occupation of the mother } \\
\hline House wife & 161 & 40.2 \\
\hline Employee & 179 & 44.7 \\
\hline Student & 15 & 3.8 \\
\hline Merchant & 31 & 7.8 \\
\hline Daily labourer & 14 & 3.5 \\
\hline \multicolumn{3}{|l|}{ Husband education } \\
\hline Unable to read and write & 9 & 2.3 \\
\hline Read and write & 15 & 4 \\
\hline primary(1-8 ) & 52 & 14 \\
\hline secondary (9-12) & 122 & 32.4 \\
\hline Higher education & 178 & 47.3 \\
\hline \multicolumn{3}{|l|}{ Husband occupation } \\
\hline Job seeker & 7 & 2 \\
\hline Government employees & 106 & 28 \\
\hline Self-employees & 159 & 42 \\
\hline Merchant & 93 & 25 \\
\hline Labor work & 11 & 3 \\
\hline
\end{tabular}




\section{Monthly income}

$\begin{array}{lll}<700 \text { Birr } & 23 & 5.8 \\ 700-2000 \text { Birr } & 76 & 19 \\ >2000 \text { Birr } & 301 & 75.2\end{array}$

* (Divorce, Widowed), ** (Protestant catholic), *** (Oromo, Tigre)

Table 2 Reproductive and maternal health service use-related characteristics of the study participants in Injibara town, Northwest Ethiopia, June 2019(n=400) 


\begin{tabular}{|c|c|c|}
\hline \multicolumn{3}{|l|}{$\begin{array}{l}\text { Variable } \\
\text { Parity }\end{array}$} \\
\hline Parity & & \\
\hline 1 child & 17 & 4.3 \\
\hline 2-4 children & 202 & 50.5 \\
\hline$\geq 5$ children & 181 & 45.2 \\
\hline \multicolumn{3}{|l|}{ Birth interval $(\mathrm{n}=383)$} \\
\hline$<2$ years & 97 & 25.3 \\
\hline $2-3$ years & 141 & 36.8 \\
\hline 3-4 years & 126 & 32.9 \\
\hline$>4$ years & 19 & 5 \\
\hline Discuss about PPFP with partner $(\mathrm{n}=376)$ & 301 & 80 \\
\hline Yes & 75 & 20 \\
\hline \multicolumn{3}{|l|}{ No } \\
\hline Previous use of family planning & 242 & 60.5 \\
\hline Yes & 158 & 39.5 \\
\hline No & & \\
\hline \multicolumn{3}{|l|}{ Number of ANC visit } \\
\hline One $\quad$ ANC visit & 42 & 10.5 \\
\hline Two ANC visit & 65 & 16.3 \\
\hline Three ANC visit & 134 & 33.5 \\
\hline Four and above ANC visit & 159 & 39.7 \\
\hline \multicolumn{3}{|l|}{ Family planning counselling during ANC } \\
\hline Yes & 127 & 31.8 \\
\hline No & 273 & 68.2 \\
\hline \multicolumn{3}{|l|}{ Previous history of abortion } \\
\hline Yes & 37 & 90.7 \\
\hline No & 363 & 9.3 \\
\hline \multicolumn{3}{|l|}{ Place of delivery } \\
\hline Governmental health institution & 341 & 85.2 \\
\hline Private health institution & 54 & 13.5 \\
\hline Home & 5 & 1.3 \\
\hline \multicolumn{3}{|l|}{ Postnatal care } \\
\hline Yes & 162 & 40.5 \\
\hline No & 238 & 59.5 \\
\hline \multicolumn{3}{|l|}{ Postpartum period(wk) } \\
\hline$\leq 6$ week & 69 & 17.2 \\
\hline 6-12 week & 100 & 25 \\
\hline 13-24 week & 146 & 36.5 \\
\hline 25-36 week & 70 & 17.5 \\
\hline 37-48 week & 15 & 3.8 \\
\hline \multicolumn{3}{|l|}{$\begin{array}{l}\text { Getting linkage to family planning by professional during child } \\
\text { immunization }\end{array}$} \\
\hline Yes & 185 & 46.2 \\
\hline
\end{tabular}




\begin{tabular}{|l|l|l|} 
No & 215 & 53.8 \\
\hline Menses resumed after recent childbirth & & \\
Yes & 219 & 54.8 \\
No & 181 & 45.2 \\
\hline
\end{tabular}

Table 3 Knowledge related characteristics of mothers during postpartum period in Injibara town, Northwest Ethiopia, June 2019

\begin{tabular}{|c|c|c|c|}
\hline Variables & Category & Frequency & $(\%)$ \\
\hline \multirow{2}{*}{$\begin{array}{l}\text { Heard about modern contraceptive } \\
\text { methods }\end{array}$} & Yes & 400 & 100 \\
\hline & No & 0 & 0 \\
\hline \multirow[t]{2}{*}{ Pills } & Yes & 297 & 74.2 \\
\hline & No & 103 & 25.8 \\
\hline \multirow[t]{2}{*}{ Injectable } & Yes & 370 & 92.5 \\
\hline & No & 30 & 7.5 \\
\hline \multirow[t]{2}{*}{ Emergency pills } & Yes & 39 & 10 \\
\hline & No & 361 & 90 \\
\hline \multirow[t]{2}{*}{ Condom } & Yes & 9 & 2 \\
\hline & No & 391 & 98 \\
\hline \multirow[t]{2}{*}{ IUCD } & Yes & 52 & 13 \\
\hline & No & 348 & 87 \\
\hline \multirow[t]{2}{*}{ Permanent } & Yes & 34 & 8.5 \\
\hline & No & 366 & 91.5 \\
\hline \multirow[t]{2}{*}{ Implant } & Yes & 236 & 59 \\
\hline & No & 164 & 41 \\
\hline \multirow[t]{2}{*}{ Knowledge } & Good Knowledge & 248 & 62 \\
\hline & Poor Knowledge & 152 & 38 \\
\hline \multirow[t]{2}{*}{ Attitude } & Favourable Attitude Unfavourable & 186 & 46.5 \\
\hline & Attitude & 214 & 53.5 \\
\hline
\end{tabular}

Table 4 Time started using contraceptive method women during postpartum period in Injibara town, Northwest Ethiopia, June 2019. 


\begin{tabular}{lll}
\hline Postpartum period & Frequency & $\%$ \\
\hline$<6$ weeks & 39 & 16.7 \\
6 week -3 month & 103 & 44 \\
\hline 3-6 month & 48 & 20.5 \\
\hline 6-9 month & 32 & 13.7 \\
\hline 9-12 month & 12 & 5.1 \\
\hline Started contraceptive use relation to menses & & \\
Before menses resumes & 18 & 7.7 \\
\hline In the same week when menses resumes & 67 & 28.6 \\
\hline After menses resumes & 149 & 63.7
\end{tabular}

Table 5 Factors associated with use of modern contraceptives during postpartum period in Injibara town, Northwest Ethiopia, June 2019 ( $\mathrm{n}=400)$ 


\begin{tabular}{|c|c|c|c|c|c|}
\hline \multirow{2}{*}{ Variables } & \multicolumn{5}{|l|}{ PPFP use } \\
\hline & Yes & No & $\operatorname{COR}(95 \% \mathrm{CI})$ & $\operatorname{AOR}(95 \% \mathrm{CI})$ & $\begin{array}{l}\mathrm{P} \text { - } \\
\text { value }\end{array}$ \\
\hline \multicolumn{6}{|l|}{ Maternal education } \\
\hline Unable to read & $8(3.4)$ & $13(8)$ & 1 & 1 & \\
\hline \&write & $18(7.7)$ & $9(5.4)$ & $3.25(0.98-$ & $3.76(0.84-$ & 0.083 \\
\hline Can read and write & $45(19.2)$ & $54(32.5)$ & 10.68) & 16.78) & 0.105 \\
\hline primary $(1-8)$ & $73(31.2)$ & $36(21.6)$ & $1.35(0.52-3.56)$ & $2.69(0.81-$ & 0.008 \\
\hline secondary (9-12) & $90(38.5)$ & $54(32.5)$ & $3.29(1.25-8.67)$ & $8.95) 5.02(1.53-$ & 0.015 \\
\hline \multirow[t]{3}{*}{ Higher education } & & & $2.71(1.06-6.95)$ & 16.47) & \\
\hline & & & & $4.25(1.32-$ & \\
\hline & & & & 13.64) & \\
\hline \multicolumn{6}{|l|}{ Number of ANC } \\
\hline One ANC Visit & $13(5.6)$ & $29(17.4)$ & 1 & 1 & \\
\hline Two ANC Visit & $33(14)$ & $32(19.3)$ & $2.3(1.02-$ & $2.23(0.85-$ & 0.103 \\
\hline Three ANC visit & $87(37.2)$ & $47(28.3)$ & $5.19)$ 4.13(1.96- & $5.86)$ 4.74(1.94- & 0.001 \\
\hline \multirow{2}{*}{ Four and above } & $101(43.2)$ & $58(35)$ & 8.69) & $11.54) 5.9(2.42-$ & 0.001 \\
\hline & & & $3.89(1.87-8.06)$ & $14.39)$ & \\
\hline \multicolumn{2}{|c|}{ FP counseling during ANC } & \multirow{4}{*}{$\begin{array}{l}30(18) \\
136(82)\end{array}$} & \multirow{4}{*}{$\begin{array}{l}3.21(2-5.15) \\
1\end{array}$} & \multirow{4}{*}{$\begin{array}{l}2.81 \\
4.86) \\
1\end{array}$} & 0.001 \\
\hline YES & $97(41.5)$ & & & & \\
\hline $\begin{array}{l}\text { ILS } \\
\text { No }\end{array}$ & $137(58.5)$ & & & & \\
\hline No & & & & & \\
\hline
\end{tabular}

History of abortion

$\begin{array}{llllll}\text { Yes } & 31(13.2) & 6(3.6) & \mathbf{4 . 0 7 ( 1 . 6 6 - 1 0 )} & \mathbf{3 . 9 3 ( 1 . 4 3 -} & \mathbf{0 . 0 0 8} \\ \text { No } & 203(86.8) & 160(96.4) & 1 & \mathbf{1 0 . 8 4 )} & \\ & & & & 1 & \end{array}$

Previous use of FP

\begin{tabular}{|c|c|c|c|c|c|}
\hline Yes & $154(65.8)$ & $88(53)$ & $1.71(1.14-2.56)$ & $1.43(0.87-2.35)$ & 0.159 \\
\hline No & $80(34.2)$ & $78(47)$ & 1 & 1 & \\
\hline $\begin{array}{l}\text { Postnatal care } \\
\text { Yes } \\
\text { No }\end{array}$ & $\begin{array}{l}116(49.6) \\
118(50.4)\end{array}$ & $\begin{array}{l}46(27.7) \\
120(72.3)\end{array}$ & $\begin{array}{l}2.56(1.68 \\
3.93) \\
1\end{array}$ & $\begin{array}{l}1.79(1.09-2.96) \\
1\end{array}$ & 0.024 \\
\hline $\begin{array}{l}\text { Menses return after } \\
\text { birth } \\
\text { Yes } \\
\text { No }\end{array}$ & $\begin{array}{l}158(67.5) \\
76(32.5)\end{array}$ & $\begin{array}{l}61(36.7) \\
105(63.3)\end{array}$ & $\begin{array}{l}3.58(2.36-5.43) \\
1\end{array}$ & $2.84(1.77-4.57)$ & 0.001 \\
\hline \multicolumn{6}{|c|}{ Resumed sexual activities } \\
\hline $\begin{array}{l}\text { Yes } \\
\text { No }\end{array}$ & $\begin{array}{l}127(54.3) \\
107(45.7)\end{array}$ & $\begin{array}{l}53(32) \\
113(68)\end{array}$ & $\begin{array}{l}2.53(1.67 \\
3.83) \\
1\end{array}$ & $\begin{array}{l}2.86(1.71-4.78) \\
1\end{array}$ & 0.001 \\
\hline
\end{tabular}

\section{Attitude}

Favourable Attitude $\quad 121(51.7) \quad 65(39.2) \quad \mathbf{1 . 6 6 ( 1 . 1 - 2 . 4 9 )} \quad 1.58(0.97-2.56) \quad 0.064$ 
Unfavourable Attitude

113(48.3)

$101(60.8)$

1

1

\section{Knowledge of FP}

Good knowledge

$160(68.4) \quad 88(53)$

Poor knowledge

74(31.6) 78(47)

$\begin{array}{llll}\mathbf{1 . 9 2 ( 1 . 2 7 - 2 . 8 9 )} & 1.075 \\ 1 & 1.80) & (0.640- & 0.785 \\ & 1\end{array}$

\section{Figures}

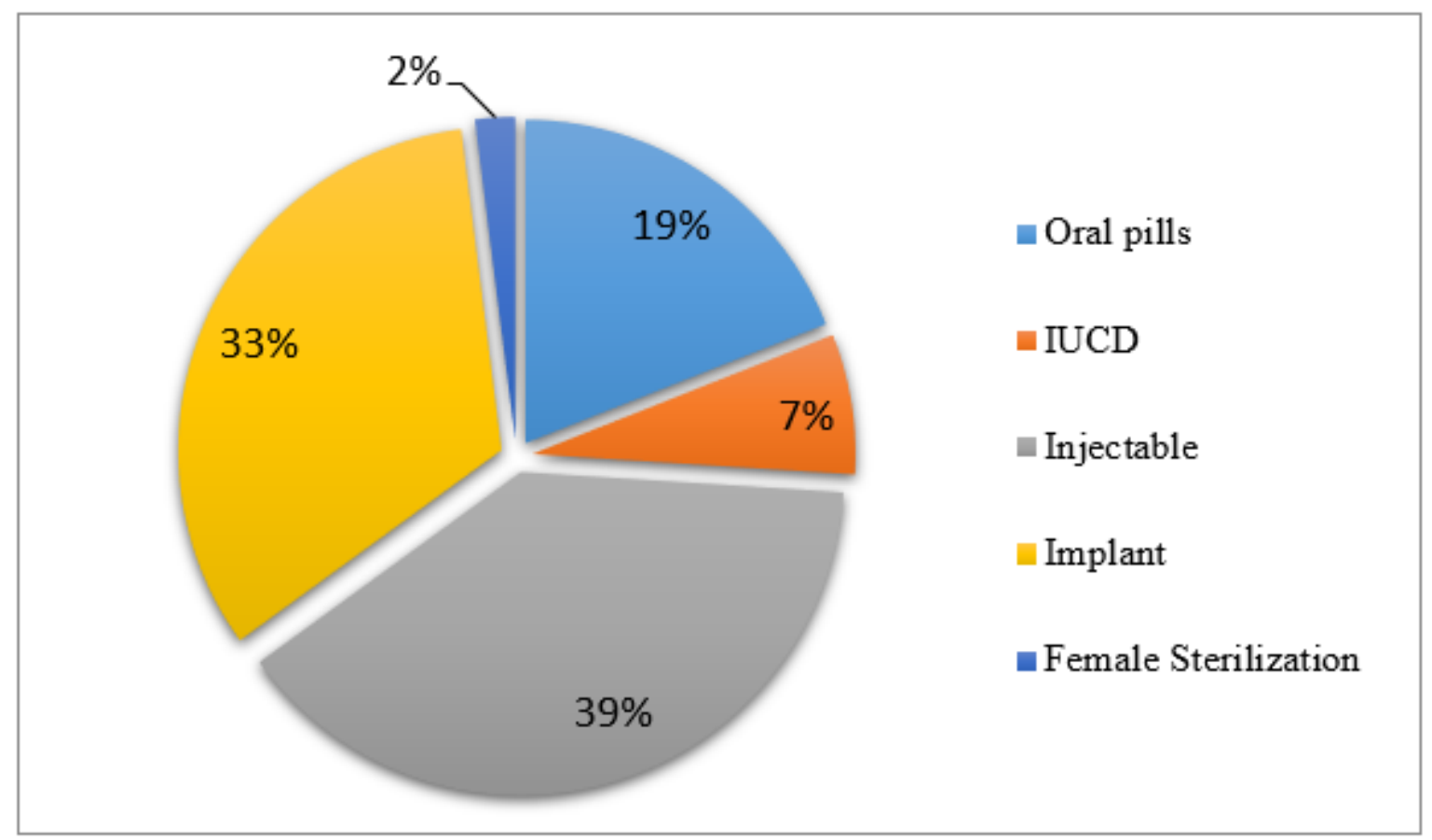

Figure 1

Pie chart show percentage of current users of modern family planning methods during postpartum period in Injibara town, Northwest Ethiopia, June 2019. 


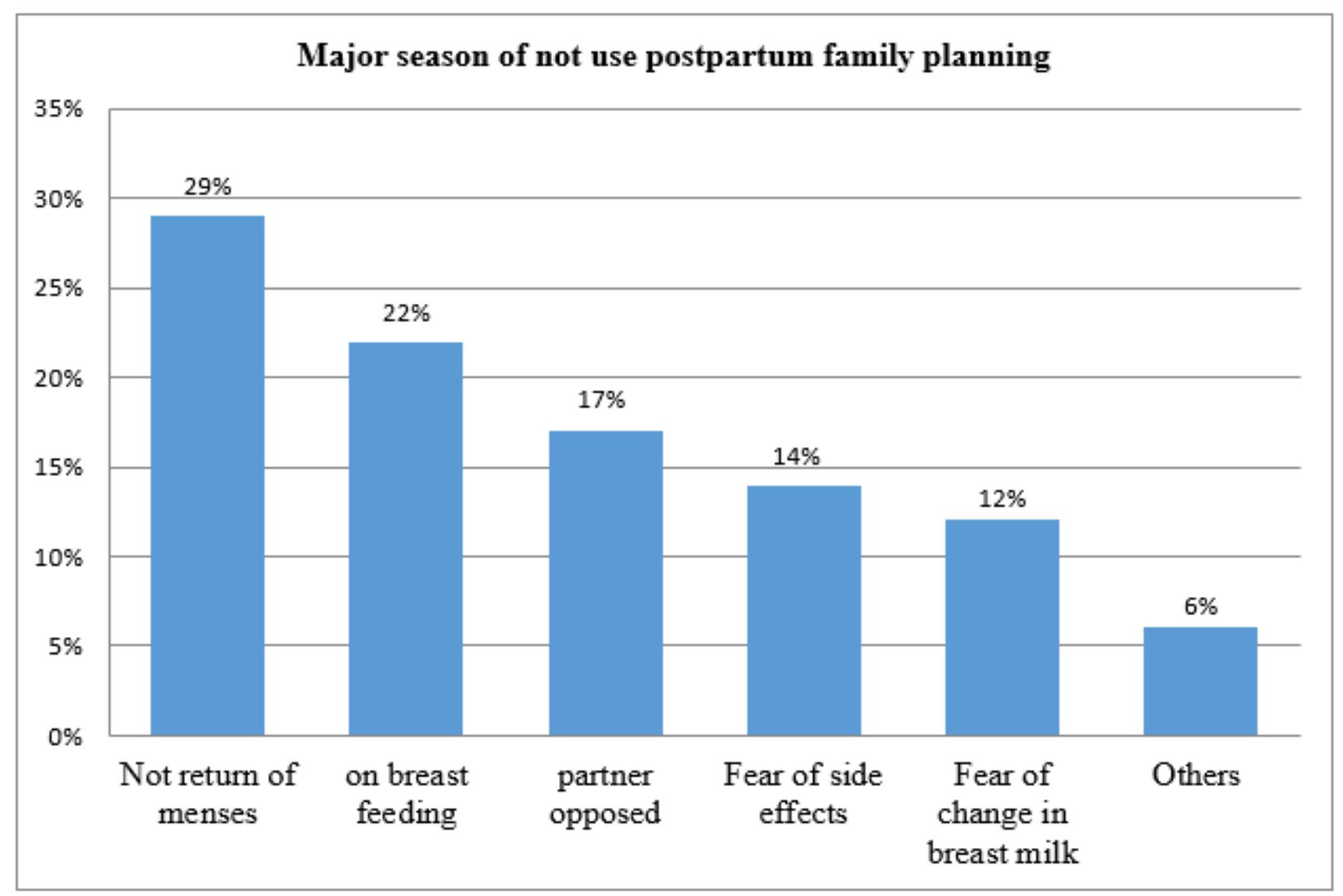

\section{Figure 2}

Major reasons for not using modern contraceptives during postpartum period in Injibara town, Northwest Ethiopia, May 2019 (Others include: Religion prohibition, want to deliver soon, separate from their husband and don't know FP methods). 